\title{
Impact of Climate Change on Agriculture in Kavre District, Nepal
}

\author{
Mira Giri \\ Lumbini International Academy of Science \& Technology, Lalitpur, Nepal \\ girimeera23@gmail.com \\ Dhundi Raj Dahal \\ dhundirajdahal@yahoo.com
}

\begin{tabular}{l} 
Article History \\
Received August 30, 2020 \\
Accepted October 12, 2020 \\
\hline
\end{tabular}

\section{Abstract}

This study aims to assist the impact of climate change on agriculture in Banepa municipality, as a case study to the local climatic trends and its impacts, vulnerability, and adaptation. The study was conducted among the household of ward no. one to eleven except two and six in the municipality. A questionnaire survey, field observation, in-depth interview, and focus group discussion, methods were adopted for the information collection, cross-validation with verification, and using the secondary source of the information. Monthly precipitation and monthly minimum and maximum air temperatures data of Dhulikhel station were used to study their annual and seasonal trends.Agriculture is one of the vulnerable sectors of the impact of climate change. Trend analysis of temperature and precipitation over 27 years indicates that this region is facing various weather variability. The annual mean of the minimum temperature was showing the highest (13.530C) in 2014 and the lowest (7.860C) in 2001. The trend analysis shows that the annual average minimum temperature has also been increasing per year. Drought, delay in monsoon, hailstorm, and heavy rainfall are major challenges in agriculture. The study concluded that climate change affected the negative impact on agriculture in the Banepa Municipality of Kavre. The existing local and institutional strategies are not sufficient and sustainable to cope with climatic vagaries. There is a proactive need for climate change adaptation measures to address the negative impact of climate change in agriculture to sustain the food and nutrition security in the community through institutional support and long-term agricultural policy and strategic plan.
Corresponding Editor

Ramesh Raj Kunwar

kunwar.dr@gmail.com 


\section{Background}

Globally, climate change is the most extreme ecological hazard that unfavorably influences agriculture sectors than in various regions. The Intergovernmental Panel on Climate Change (IPCC, 2013) charaeterized climate change refers to a change in the state of climate that can be identified by changes in the mean variability of its properties and that persists to an extended period normally decades or more. The linear trend on the global average surface temperature from 1880 to 2012 showed that the earth's surface temperature has increased by 0.85 [0.65 to 1.06$] 0 \mathrm{C}$ (IPCC, 2013). The AR5 report has revealed that the number of cold days and nights has diminished through the number of warm days and nights has increased a global scale since 1950. Climate change impact has been experienced in different sectors in Nepal including agriculture, forest and biodiversity, water resources, and energy. Nepal is one of the most vulnerable countries to climate change in the world. Moreover, changes in rainfall patterns, insufficient water supply for crops, extreme weather incidents, the spread of pests, and crop disease have been directly affecting crop production and hence on food and nutritional security. Agricultural productivity has remained stagnant or declined across the nation.

In the national context, a higherpercentage of the population is engaged in agriculture. Many studies in the past show that climate change is affecting the agricultural production system in Nepal directly or indirectly. The livelihood of two-third of the labor force in rural areas of Nepal will be affected if agriculture production is adversely impacted by climate change (Pant, 2012). Although the amount of precipitation varies significantly across the country, there is a shift in monsoon periods, intense and unpredictable rainfall patterns. The temperature across the country shows tendencies towards the increasing trend. Drying of water sources, erosion, and landslides in hills and mountain regions of Nepal while flooding of cultivated lands in low-lying areas of hills and Terai regions are the direct impacts of climate change in Nepalese agriculture. Climate change and its hazards, at the present scenario of environmental crisis, have appeared as most threats especially to the small, rural farmers of the poor nation depending upon the natural climatic cycle where there is no scientific irrigation system.

The main objective of this study was to find out the impact of climate change on cereal crops in the study area. This research was conducted to study trends on change in climate and the impacts of climate variations in the major crop production systems.

The study was important and relevant. Climate change and its hazards, at the present scenario of environmental crisis, have appeared as most threats especially to the small, rural farmers of the poor nation depending upon the natural climatic cycle where there is no scientific irrigation system. Farming is one of the most sensitive sectors in response to the weather conditions of wind, rainfall, hailstorm, snowfall, drought and temperature. So, the farmers of Nepal are at high risk and the wailing of the suffered hearts started to notice as the impacts are rampant. At the same time, these farmers have also adapted some of the adaptation strategies to reduce the impacts of changing weather conditions based on their knowledge and experience. In the context of the study area, the Banepa Municipality of 
various wards in Kavre has been chosen. This type of local study has not been carried till date since this is the research gap in this field, therefore, the impact of climate change on major cereals crops seems to be significant in Banepa Municipality, Kavre district, Nepal. Banepa, a municipality, and the historical town are in Kavre valley situated at about an altitude of 4,800 $\mathrm{ft}(1,500 \mathrm{~m})$ above sea level in the Bagmati Zone of Nepal which is at about 25 kilometers (16 miles) east from Kathmandu.At the time of the 2011 Census, it has a population of 24,764 .

\section{Review of literature}

\section{$>$ Climate change}

Climate change is a real, crucial and certainly a global problem over a long period of time. IPCC (2013) mentioned that if mankind continues the consumption of fossil fuels at its current level, the average temperature of the earth will rise by $6.40 \mathrm{C}$ and sea level will rise by $59 \mathrm{~cm}$ by way of the cease of the twenty-first century. Upreti (1999) described climate change as a phenomenon due to emissions of greenhouse gases from gas combustion, deforestation, urbanization, and industrialization, resulting in variants in solar energy, temperature, and precipitation. Climate change is a real hazard to many organisms in theworldasit impactsall environments, whichincludefreshwaterhabitat, oceans, forests, and different vegetation. Climate change impacts water sources and agriculture, and geological processes such as landslides, floods, desertification, and in long-term meals safety and human health (Malla, 2008).

Globally, the charge of warming in the Hindu Kush Himalaya region is notably higher than the average (ICIMOD, 2010). Warming has also been greater in the western part of the country than in the eastern part (Malla, 2008). Continuous warming and a rise in maximum temperature at the rate of 0.04 to $0.060 \mathrm{C}$ annually (MoPE, 2010). Temperatures are said to have negative impacts on cereals yield that's if temperatures increase the yield of cereals will reduce significantly. The contribution of agriculture to the GDP of Nepal exceeded 50 percent 25 years ago. It is decreasing over the years; however, it still exceeds 27 percent (NPC, 2019). An increase in temperature and CO2 will lead to an increase in the population of pests and the severity of diseases in the presence of host plants. It increases the rate of the reproductive cycle of insects and pests. Malla (2008) recognized the increase in insect population leads to demand for more use of pesticides, which unknowingly causes lots of harm to the ecosystem as well as human society.

\section{Climate change impacts on agriculture}

Agriculture in Nepal is more vulnerable to climate change because $64 \%$ of the cultivated land is rain-fed and two-third of the population has agriculture-based livelihood (FAO, 2004). Climate change conditions such as rising temperatures, delayed monsoon, increased annual rainfall, and increased occurrence of intense rainfall that has already affected many rain-fed farmers in Nepal (Regmi \& Adhikari, 2007). Climate change affects agriculture in several ways, including through changes in average temperatures, rainfall, and climate 
extremes with an important impact on soil erosion (i.e. floods, drought) changes in pests and diseases, changes in atmospheric carbon dioxide, changes in the nutritional quality of some foods, changes in the growing season, and changes in sea level. Crop yields show a strong correlation with temperature change and with the duration of heat or cold waves and differ based on plant maturity stages during extreme weather events (Hoffmann, 2013). Crop growth and development, as well as different physiological processes, are highly influenced by climate. Land preparation, date of sowing, irrigation, harvesting, and other forms of activities are also affected by climate.

Over the past three years, the delay in monsoon season experienced in Nepal has changed the cropping pattern and crop maturity period which has delayed the planting and harvesting season by a month, which has, in turn, affected rotation practices (Dahal et al., 2011). A drought in the eastern region of Nepal decreased the rice production by $30 \%$ in 2006 and heavy flooding in the mid-Western and far. Western regions in 2006 and 2008 destroyed crops (Practical Action, 2008).

Croplands in the mountain region of Nepal are environmentally marginal and are likely to be at increased risk of land degradation and biodiversity loss as a result of climate trends. Nepalese farmers are largely poor with limited access to external resources and are likely to be particularly vulnerable to climate change. Vulnerability to climate change is closely related to poverty, as the poor are least able to respond to climatic stimuli (Olmos, 2001). Besides, biophysical features of the region further increase vulnerability.

\section{Climate change impacts and vulnerability of soil}

Soil may be a crucial common valuable asset that directly or indirectly helps all forms of life on the planet earth. According to Reale et al. (1995) the soil is holistically described as a social good; it represents the physical, chemical, biological base of the agrarian production. The decline in agricultural productivity might also be related to influences changes in climate components have on soil quality, particularly its overall capacity to support life and suitability for sustainable alternative uses. The vulnerability of soil to climatic impact depends on each of the physical and chemical characteristics of soils. Climate is probably the main variable that influences, directly or indirectly the topsoil, and particularly the surface layer. Other surface processes are caused by the properties of the soil itself (Pla, 2002).

Acid rainfall which is an outcome of climate change with its implications of greenhouse gases adds to the acidity of the soil. In South and South-East Asia, the principal soil degradation processes associated with land-use changes include accelerated erosion by water and wind, salinization, flooding, waterlogging, and soil fertility. The pace of soil degradation issue is the highest in the mountains because of the fragile environment and the steep slopes (Acharya \& Kafle, 2009). Moreover, due to rugged mountainous topography, active tectonics, and concentrated monsoon precipitation, Nepal is naturally highly vulnerable to soil erosion on slopes and flooding in the low-lands. 


\section{Climate change adaptation of agriculture}

Adaptation is the alert adjustment in natural or human-managed framework to minimize the impacts. Farmers are experiencing an increase in temperature and sporadic precipitation. They have started adjusting to climate change by using their local knowledge and practices as possible. According to Smit and Skinner (2002), adaptation on agriculture can be categorized as innovative, on-farm adjustment practices, government policy including insurance as well as diversifying household income sources as financial management strategies. The farmers who have the resources and access should be able to adapt better as compared to resource-poor marginal farmers (Esterling \& Apps, 2005). Famers can adapt to climate change to some extent by adjusting planting time and input use, by altering soil management practices as well as diversifying their farm enterprises. In South Asian countries, particularly India, Nepal, and Bangladesh, farmers are already adapting to changing conditions by using improved/hybrid seed practices (Gautam, 2008).

Climate variability and risks have continuously been a portion of agriculture, due to which farmers have created numerous ways of overseeing dangers. Traditional farming system management practices and farmers' innovations are a key element in local adaptation to climate change. While researchers and policymakers work to find solutions, local farmers have already amassed considerable experience ofhow to cope, based on their observation and experimentation in the field (Reid \& Swiderska, 2008). So, it is very important to document the adaptation practices that have been evolved in the farmers' fields.

\section{Materials and methods}

The main purpose of this study is to reduce the impact of climate change on crops from the local level. The quantitative and qualitative, mixed-method was applied. The questionnaire survey, focus group discussion, in-depth interview, and field observation were the major tools used for this study.

For the study, nine various wards (1 to 11 except 2 and 6) of the Banepa Municipality were selected as a study area. The sample size formula available in many survey texts e.g. see Babble, 1990; Fowler, 2002 (Creswell, 2009),two hundred households were surveyed to fill up the questionnaire on a random basis with sample interval used by various researchers such as Schofield (2006), Kalton(1983) and Cochran (1977) was also used for this purpose (Dahal, 2019). The questionnaire survey was conducted with one of the household members. The sample size adopt from ward no. 1,3,4 and 5 was 12, 17, 17 and 26, whereas $7,8,9,10$, and 11 was followed by $24,35,29,29$, and 11 respectively.

Both primary and secondary data were the sources used for the study purpose. Firstly, the primary data has been planned to be obtained through preliminary interviews and discussions with concerned officials, experts, and local people. Secondly, semi-structured in-depth interviews with various key players and stakeholders of the selected study area were conducted. Initially, the questionnaire was prepared in English and piloted, corrected to make clearerfor the respondents then translated for the local language Nepali to ease the 
survey. After the survey, the questionnaire was translated into English for data entry and then analyzed. Other than filling the interview schedules, detailed information provided by the respondents during discussions has been planned to be recorded by taking notes. The audio recording was used and followed ethical consideration. The pilot study was conducted to ensure the readability and understandability of questionnaires, in-depth interview, and focus group discussion schedules then final data were collected. The primary source of information on a range of issues (sowing time, germination period, irrigations required, use of chemical fertilizer, harvesting time, new diseases, and weeds) was prepared to investigate the trend and effect of climate associated factors on farming.

The researcher had also collected the secondary source of information from relevant study reports,published and unpublished documents and maps were also collected from various governmental and non-governmental organizations. The climatic parameters data were obtained from the Department of Hydrology and Meteorology (DHM), Government of Nepal. In the present study, climate variables ofKavre district were taken for the study purpose. The climate variables such as temperature, rainfall were utilized to explore the relation of climate to cereal crop yields based on 27 years of records. In the present study, the data of temperature and rainfall from 1993-2019 of the Dhulikhel station was used. The data of cereal yields of Kavre district from 1993-2019 were used and were taken from the Ministry of Agriculture Livestock and Development (MoALD) was taken for the study purpose.The survey was conducted from February 26 to March 14, 2020. After collecting the qualitative and quantitative information, the researcher was analyzed and interpretation the data by using Statistical Package for Social science (SPSS 21.0 Version), and Microsoft Excel-2013. Both descriptive and analytical methods were used to analyze data.

\section{Result and discussion}

\section{$>$ Annual mean rainfall}

Annual mean monthly precipitation data (1993-2019) of Dhulikhel Meteorological Station was found that July and August receive the highest rainfall of $375.16 \mathrm{~mm}$ and $335.16 \mathrm{~mm}$ respectively and November and December have minimum rainfall with respective rainfall of $5.15 \mathrm{~mm}$ and $8.61 \mathrm{~mm}$ as shown in figure 1 . Trend line shows the equation as $\mathrm{y}=4.6184 \mathrm{x}+88.043$ and $\mathrm{R}$-value as $\mathrm{R}^{2}=0.0162$. This equation indicates an increasing pattern in rainfall.

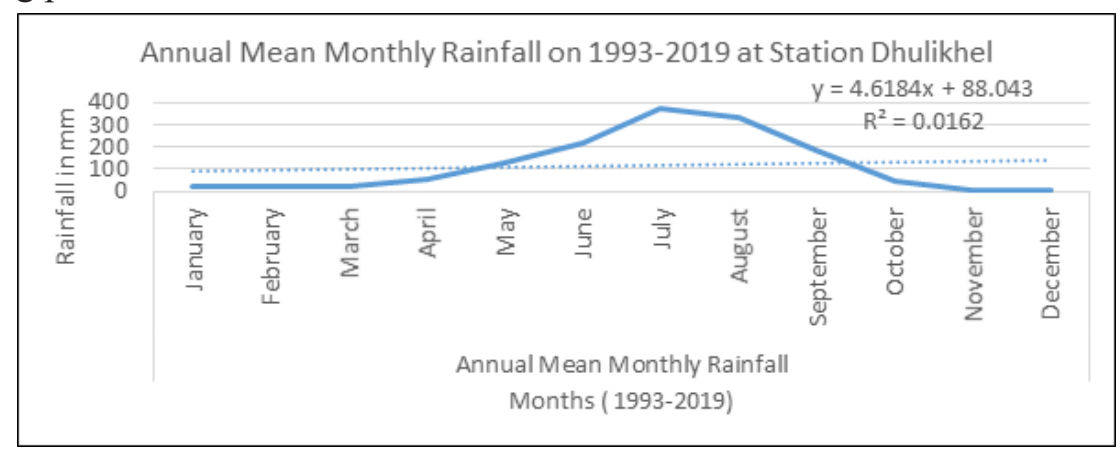

Source: DHM, 2020 
Figure 1: Average Annual Monthly Rainfall of Dhulikhel Meteorological Station

Practical Action Nepal (2009) revealed that the variation in the spatial and temporal distribution of precipitation and its trend over Nepal is due to the interaction of the complex topography with monsoon and westerly disturbances system. From computation, it was also noticed that the annual 27 years annual average mean rainfall is $106.36 \mathrm{~mm}$.

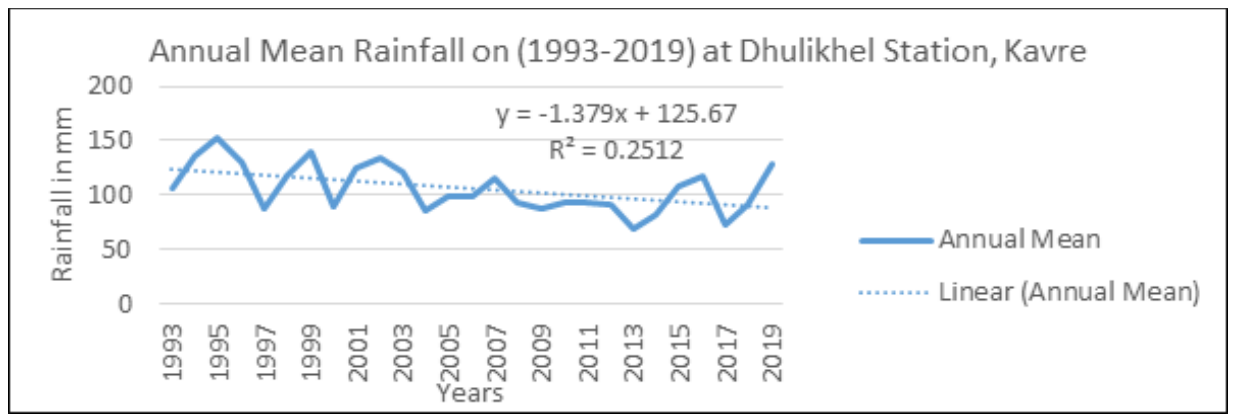

\section{Source: DHM, 2020}

\section{Figure 2: Average Annual Rainfall Dhulikhel Meteorological Station}

The average annual rainfall was fluctuating showing erratic with the maximum in 1995 i.e. $152.01 \mathrm{~mm}$ and minimum in 2013 i.e. $69.63 \mathrm{~mm}$. The mean annual precipitation of 27 years with the trend line shows the equation as $\mathrm{y}=-1.379 \mathrm{x}+125.67$ and $\mathrm{R}$-value as $\mathrm{R}^{2}=$ 0.2512 is shown in the above (figure 2). Even the trend line showed the decreasing trend of rainfall.

\section{Annual mean maximum temperature}

27 year mean monthly maximum temperature data (1993-2019) of Dhulikhel Meteorological station was analyzed. The monthly temperature analysis shows that the highest maximum temperature reaches its peak value of $26.740 \mathrm{C}$ in June while its lowest peak value of $14.700 \mathrm{C}$ in January was recorded. Trend line shows the equation as $\mathrm{y}=$ $-0.0128 \mathrm{x}+21.58$ and $\mathrm{R}$-value as $\mathrm{R}^{2}=1 \mathrm{E}-04$ in figure 3 . This equation indicates a constant trend in the mean monthly maximum temperature.

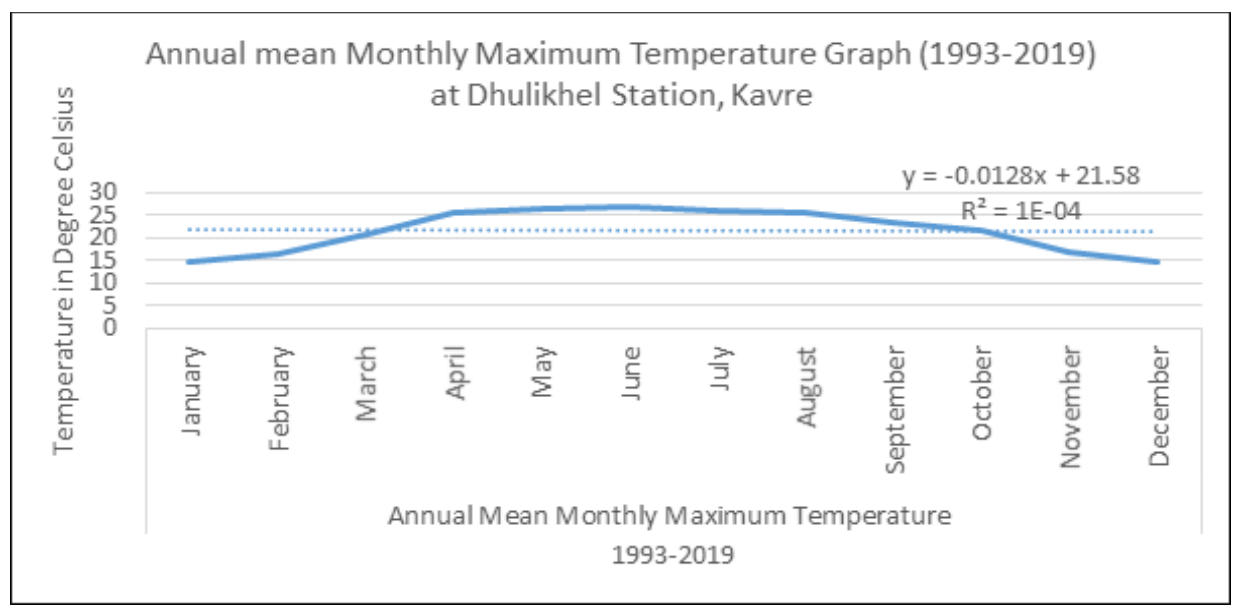

Source: DHM, 2020 
Figure 3: Average Annual Monthly Maximum Temperature of Dhulikhel Meteorological Station

From computation, it was also noticed that the annual average of monthly mean maximum temperature was 26.74 0C. Similarly, the annual mean of the maximum temperature of 27 years with a trend line of the following figure shows that maximum temperature is increasing with the equation $y=0.048 x-74.746$, and $R$ square value is $R^{2}=0.0192$ which is shown in a figure 4 graph.

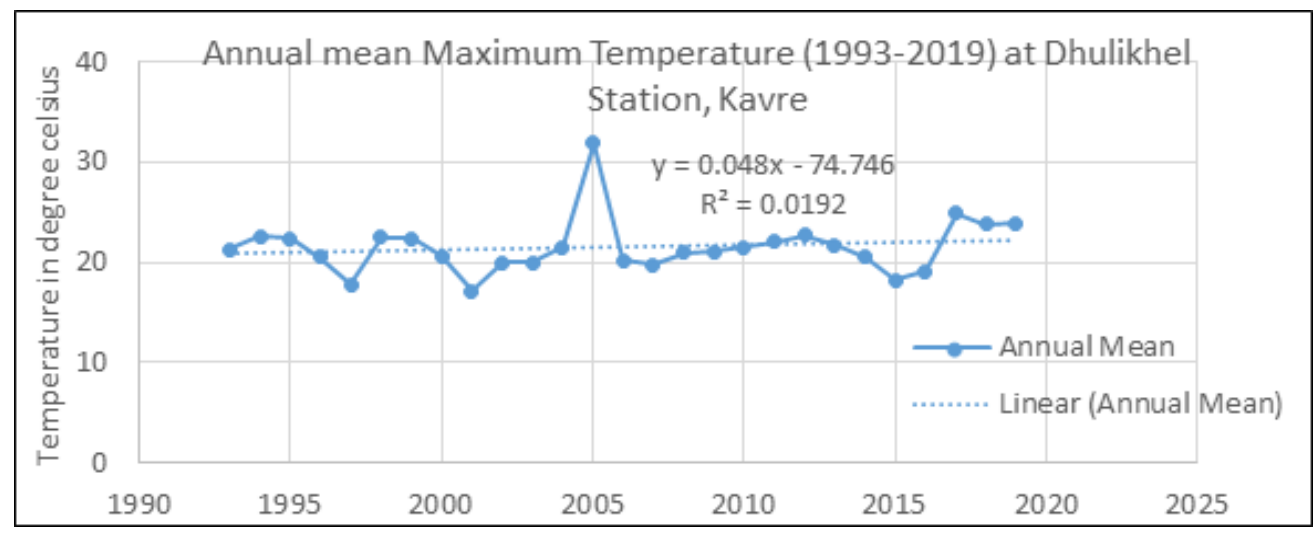

Source: DHM, 2020

Figure 4: Average Annual Maximum Temperature of Dhulikhel Meteorological Station

The annual mean of the maximum temperature was showing the highest maximum temperature in 2005 i.e. $31.840 \mathrm{C}$ and the lowest in 2001 i.e. $17.140 \mathrm{C}$. The trend shows that the annual average maximum temperature was in an increasing trend.

\section{Annual mean minimum temperature}

The 27 years mean monthly minimum annual air temperatures of Dhulikhel Meteorological station have been analyzed statistically. The average monthly minimum temperature reaches its highest peak value of $18.340 \mathrm{C}$ in August while its lowest peak value of 3.76 in January was recorded. The minimum monthly air temperature for Dhulikhel showed an increased trend however this temperature showed a tendency towards an increasing trend in figure 5.

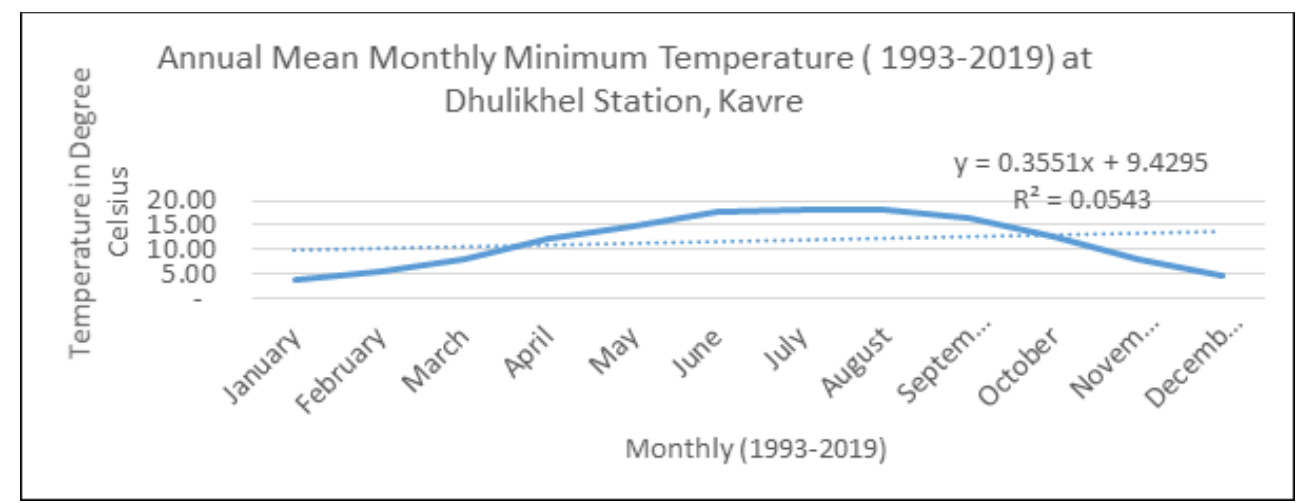

Source: DHM, 2020 
Figure 5: Average Annual Monthly Minimum Temper*ature of Dhulikhel Station

Similarly, the annual mean of the minimum temperature of 27 years with a trend line is shown in figure 6.

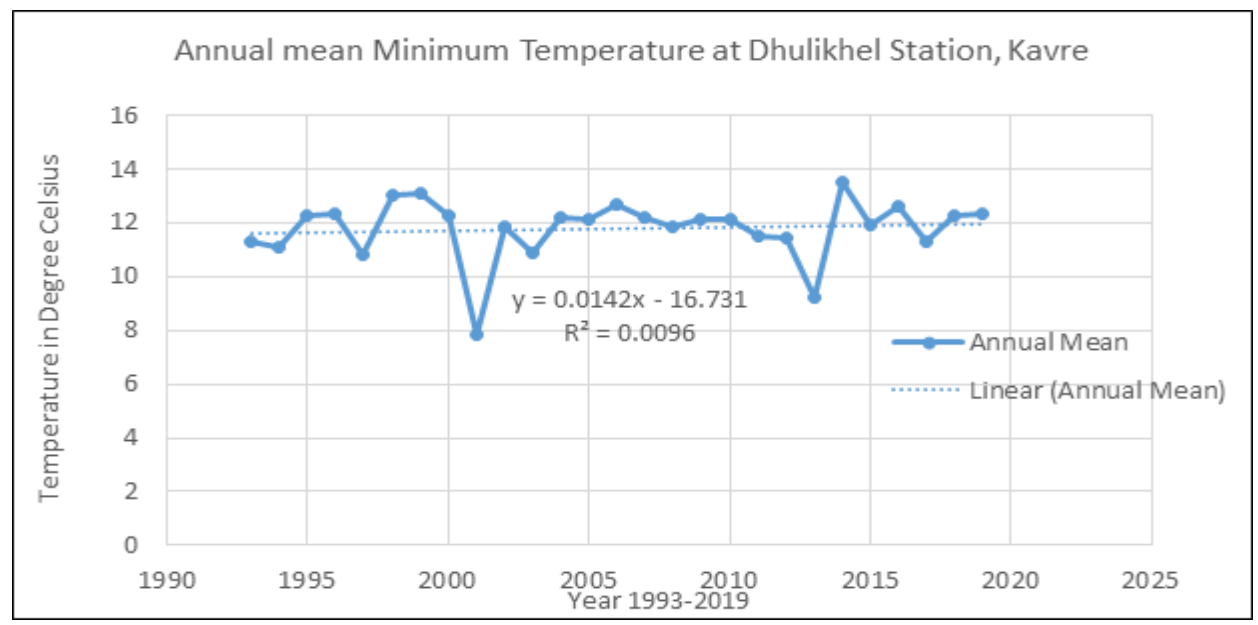

Source: DHM, 2020

Figure 6: Average Annual Minimum Temperature of Dhulikhel Station

The annual mean of the minimum temperature was showing the highest in 2014 i.e. 13.530C and the lowest in 2001 i.e. $7.860 \mathrm{C}$. This analysis shows that the annual average minimum temperature was in an increasing trend.

\section{$>$ People's perception of climate change}

Climate change is a vague subject. Different people take different for climate change. Some people do know what climate change is, some people think they know but they have not good knowledge of climate change and some people know what climate change is. Here, the household surveys were carried out to collect the community experience and perception about climate change impacts in the agricultural sector. Respondent expressed their experiences on changes in local climate and its impact on their lives. However, they are unclear about climate change and its impacts.

Perception and experience on whether they had heard about climate change and global warming were that only $13 \%$ have not heard about it and $87 \%$ have heard it directly.

\section{People's perception towards the changes in soil}

Climate change has a major impact on soil, and changes in land use and soil can either accelerate or slow down climate change. Without healthier soil and sustainable land and soil management, we cannot tackle the climate crisis, produce enough food, and adapt to a changing climate. Soil plays a crucial role in agricultural production. The changes in rainfall patterns, along with expected changes in temperature, solar radiation, and atmospheric $\mathrm{CO} 2$ concentrations, may have significant impacts on soil erosion rates. The processes involved in the impact of climate change on soil erosion by water are 
complex, involving changes in rainfall amounts and intensities, the number of days of precipitation, the ratio of rain to snow, plant biomass production, plant residue decomposition rates, soil microbial activity, evapotranspiration rates, and shifts in land use necessary to accommodate a new climate regime. Even in cases where annual rainfall would decrease, system feedbacks related to decreased biomass production could lead to greate susceptibility of the soil to erode.

According to the survey, the soil of the study area was inherently fragile and prone to degradation. Wind, landslide, and water runoff causes losses of the huge amount of topsoil during the pre-monsoon and monsoon season in the study area. From survey out of 200 respondents, $59 \%$ of respondents have observed that changes in the soil while $41 \%$ do not observe the changes in the soil. The population of observed the changes in the soil is higher, they observed that the soil becomes highly acidic and hardening. In their opinion, the soil becomes erode due to the use of the high amount of chemical fertilizer and their unfriendly behavior to the environment.

\section{$>$ Perception on trend of climate change parameters}

Concerning the perceptions of climate change, perception of change in climatic parameters like precipitation, temperature, winds/storms, fog, hailstone, cold waves, and heat waves is important.

Regarding the past and present variation in annual precipitation amount change, $11 \%$ people said that the precipitation in recent years is increasing, $76 \%$ said it is decreasing and $13 \%$ said it is the same. Similarly, regarding the variation in annual temperature, $81 \%$ replied that it is increasing, 10\% decreasing and 9\% felt in the same. Regarding the winds/ storms change $60 \%$ said is increasing in recent years, $12 \%$ responded to its decreasing trend, $15 \%$ felt the same, and do not know by $13 \%$. The fog occurrence was found to be increasing by $57 \%$, decreasing by $24 \%$, the same by $8 \%$, and don't know by $11 \%$. The hailstone amount pattern was found to be increasing by $28 \%$, decreasing by $17 \%$, the same by $43 \%$, and don't know by $12 \%$. Similarly, the cold waves days change was responded to as increasing by $24 \%$, decreasing by $62 \%$, the same by $13 \%$, and don't know by $7 \%$. The heatwave days were said to be increasing by $51 \%$, decreasing by $14 \%$, the same by $26 \%$, and not known by the remaining percentage.

\section{$>$ Impact of climatic change on agriculture}

According to the survey, the perception of the impact of climate change in agriculture was found that $86 \%$ of the community answered that there is the direct impact of climate change in agriculture and only $14 \%$ said that there is no impact. Similarly, the perception on the sensitivity of agricultural productivity with climate change reveals that $49 \%$ finds it sensitive, 23\% finds it highly sensitive, 16\% less sensitive and 12\% are unknown about it.

Based on the field survey, there is a slightly change in environmental parameters in the study area. Cold and frosty days are decreasing, the rainy season is shifting and days are becoming hot. These parameters help to impact on the agricultural system of this region. According to the community of the study area, there is a change in the production system 
of agriculture. The production rate of cereal crops like rice, maize, and wheat is going to slightly increase in recent years as a comparison of the previous year. The local people were not satisfied with the production of local varieties in different sectors of production so they were changing varieties of cereal crops, most of the farmers used improved seeds, chemical fertilizer, and pesticides because of this reason, production is increasing. Higher air temperature in the ripening period causes the crop to ripen faster, as a result of the carbohydrate in the plant steam and leaves cannot translocate properly, thus grain size becomes smaller and the yield becomes less. So crops require optimum air temperature. Crops can't tolerate high air, soil, and water temperature. And high temperature produces several problems in agriculture such as shortening the time of the reapining of crops, shortening the time of the germination of a seed, increase the number of pests and disease. There is a problem in the production of the cereal crops that are also not fixed. There are many problems in agricultural plants, sometimes rain deficit, sometimes heavy rain, flood, frost, and longtime drought. So it can be said that the climatic parameters are also affecting the crops in the study area.

\section{Adaptation measures by the farmers}

The farmers have been adopting a variety of options and technologies to adapt to the impacts of climate change in agriculture. These measures include changing crop varieties, the use of improved seeds of cereal crops, changing cropping patterns, practicing intercropping systems, terracing sloping lands to halt landslide and erosion, use of chemical fertilizers, and pesticides. Imported improved varieties have high production potential but are less resistant to climatic stresses such as windstorms, hail, and rain. Farmers of this Municipality prefer the improved varieties of rice, maize, and wheat for high productivity per unit area. The improved seed has high production potentiality as compared to the local seeds.

The survey showed that in local agriculture adaptation practice, $23 \%$ of community people changing crop varieties, $96 \%$ used improved seed. Likewise, $47 \%$ of people changing cropping patterns and intercropping are done by 64\%. Land management technology and terracing are followed by $58 \%$ and $53 \%$ respectively. Also, chemical fertilizer and pesticides used by large amounts of $93 \%$, and there is no system of water harvesting.

\section{Conclusions and recommendation}

The impact of climate change is gradually becoming a matter of great concern for every country including Nepal. The impact is affecting the poor and vulnerable farmers in Nepal, most of whom are farmers working on their farms for subsistence level. The pace of soil degradation issue is the highest in the mountains of the fragile environment and the steep slopes. Moreover, due to rugged mountainous topography, active tectonics, and concentrated monsoon precipitation, Nepal.Many sudies shows that,South Asian countries, particularly India, Nepal, and Bangladesh farmer's using imroved seed for adaptation, the context of exchanging drought-resistant seeds and other abiotic stress-tolerant crop varieties and adopting and practicing particular soil and water management 
practices for marginal areas have long been core activities of the farming communities, in this research this statement of these researchers has been tested and accepted.

This study has fulfilled the gap of research in the climate change context of cereal crops on mid- hill, Banepa Municipality of Nepal with tested the previous research.This study attempt to analyze the impact of climate change on the agriculture system of the Banepa Municipality. From the data analysis, temperature and rainfall of this region are not the same in the long range of time; the precipitation of the study area was also a decreasing trend.

The perception and experiences of the change of climatic variability reveal the fact of changing climate. Rainfall and temperature pattern is the main indicator of climate change. The average annual rainfall was recorded maximum in 1995 and a minimum in 2013. The annual mean temperature of this region is not also the same. The maximum annual mean temperature and minimum annual mean temperature are also slightly increasing. Similarly, the annual mean of maximum temperature in 2017 and 2014 recorded was highest. Farmers have experienced that the rainfall is untimely and the temperature has increased. Due to this change farmers have experienced new diseases and weeds in the field crops. The outbreak of new diseases and weeds could be the effects of climate change.

Farmers have the pursuit of different strategies to reduce the vulnerabilities of climate-related disasters. These strategies include changing crop varieties, used of improved seed, changing cropping patterns, intercropping system, land management technology, terracing, used of chemical fertilizer and pesticides. Migration, and diversification of livelihood options i.e. income. In general climate change should be considered in long term strategic planning to have the maximum adaptive capacity.

The irrigation system could be a long term solution for the untimed rainfall problem. The method of irrigation could be suggested by the concerned personnel. In the narrow fields, modern types of irrigation like drip irrigation or similar type may be in short term solutions. Further scope of research has been recommended for an integrated way through multidisciplinary research aspects in the subject of climate change to identify the in-depth impact of climate change in the case of cereal crops, water source, biodiversity, livestock and public health problems at the local and national levels with short term and long term basis.

\section{References}

Acharya, A.K. \& Kafle, N. (2009). Land Degradation Issues in Nepal and Its Management through Agro-forestry. The Journal of Agriculture and Environment, 10, 115-123.

Creswell, J. W.(2009). Research Design. New Delhi: Sage Publication.

Dahal, D. R.(2019). Ph.D Thesis. Public Participation in Environmental Management. Me war, Rajasthan, India. 
Dahal, H., Pokhrel, M. \& Pandey, B.(2011). National Adaptation Program of Actions to Climate Change: Food Security and Agro-Biodiversity Management in Nepal. Paper Presented in Special Information Seminar of CGRFA-13 on Climate Change and Genetic Resources for Food and Agriculture: State of Knowledge, Risks and Opportunities, FAO, Rome, 16 July 2011, Red Room (A-121).

Dengpan Xiao, H. B.(2018). Impact of Future Climate Change on Wheat production: A Simulated Case for China's Wheat System. MDPI, 1-15.

DHM(2019). Department of Hydrology and Meteorology, Babarmahal, Kathmandu, Nepal. Rainfall and Temperature Data of Dhulikhel State From 19932019. (www.dhm.gov.np)

Esterling, W. \& Apps, M. (2005). Assessing the Consequences of Climate Change For Food and Forest Resources: A View From the IPCC, Climate Change 70, 165-189.

FAO(2004). Compendium of Food and Agriculture Indicators

2004- Nepal retrieved on July 9, 2014, From fao.org/es/compendium 2004/pdf/ ESS NEP.pdf.

Gautam, A. K.(2008). Climate Change Impact on Nepalese Agriculture and Strategies for Adaptation. Paper Presented in NAPA Workshop Organized by LI-BIRD and Biodiversity International. 23 December 2009 (Mimeo, LI-BIRD).

Hoffmann, U.(2013). Agriculture a Key Driver and a Major Victim of Global Warming, in: Lead Article, in: Chapter 1, in Hoffmann 2013. 3-5.

ICIMOD (2010). Mountain Initiatives, International Center for Integrated Mountain Development (ICIMOD), Kathmandu, Nepal.

IPCC(2013). Climate Change 2013: The Physical Science Basis. Contribution of Working Group I to the Fifth Assessment Report of the Intergovernmental Panel on Climate Change. In: Stocker TF, Qin D, Plattner GK, Tignor M, Allen SK, Boschung J, Nauels A, Xia Y, Bex V, Midgley PM, editors. Cambridge University Press, Cambridge, United Kingdom and New York, NY, USA. 1535

Malla, G.(2008). Climate Change and Its Impact on Nepalese Agriculture. The Journal of Agriculture and Environment, 9, 62-71.

MoPE (2010). State of the Environment Nepal (Agriculture and Forest). Kathmandu: Ministry of Population and Environment, HMG.

NPC (2019). Tenth Plan, 2019/20-2020/21.National Planning Commission, Government of Nepal Kathmandu: National Planning Commission, Singha Durbar.

Olmos, S.(2001). Vulnerability and Adaptation to Climate Change: Concepts, Issues, Assessment Methods; Climate Change Knowledge Network. 
Pant, K.P.(2012). Climate Change and Food Security in Nepal.The Journal of Agricultural and Environment, 13(5).

Pla, I.(2002). Hydrological approach to soil and water conservation. In:"'Man and Soil at 'the Third Millenium.”. (J. L. Rubio et al., ed.). 1, 65-87. Geoforma Ed. Logrono (Spain). ISBN 84-87779-45-X)

Pokharel, B. S.(2019). The east-west division of changing precipitation in Nepal. International Journal of Climatology.

Practical Action(2008). Promoting Adaptation to Climate Change in Nepal. Policy Briefing, Nepal, Kathmandu: Practical Action.

Practical Action Nepal,(2009). Climate Change and Adaptation in Nepal. A Field Report Submitted by Small Earth Nepal (SEN) to Practical Action Nepal Office. Kathmandu: Practical Action.

Reale, Nori, L. M. \& Ferrari, G.(1995). The Holistic Approach through a Questionnaire: From Soil Science Towards Sustainable Development. In: Holistic Approach to Sustainable Development: Interaction of Soil Science with Different Disciplines. Proceedings of Bologna Workshop 15th-19th September, 1995. 44-54.

Regmi, B. \& Adhikari, A.(2007). Human Development Report 2007: Climate Change and Human Development-Risk and Vulnerability in Warming World; Country Case Study-Nepal.,New York, United Nations Development Programme.

Reid, H. \& Swiderska, K.(2008). Biodiversity, Climate Change and Poverty: Exploring the Links. International Institute for Environment and Development (IIED) Briefing Paper.

Smit, B. \& Skinner, M.W.(2002). Adaptation Options in Agriculture to Climate Change: A Typology. Mitigation and Adaptation, Strategies for Global Change 7, 85-114.

Upreti, D.C.(1999). Rising Atmospheric CO and Crop Response. SASCOM Scientific Report, 1-8. World Climate News, 2006. Homing in on Rising Sea-levels. June 29, 2006. 